\title{
A new paradigm for functional urology
}

\author{
Blayne Welk, MD, MSc, FRCSC
}

Division of Urology, Department of Surgery, Western University, London, ON, Canada

Cite as: Can Urol Assoc J 2019;13(6):208. hitp://dx.doi.org/10.5489/cuaj.6037

See related article on page 203

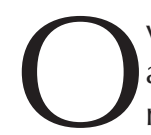

veractive bladder is a common clinical diagnosis affecting $10-20 \%$ of the population. ${ }^{1}$ For the vast majority of people, this is a chronic condition. ${ }^{1}$ It has a significant impact on overall quality of life and mental health (similar to diabetes) ${ }^{2,3}$ and has a financial impact in the billions of dollars. ${ }^{4}$ Baverstock and colleagues describe a remarkable shift in the way Calgary chooses to deliver care to men and women with lower urinary tract symptoms (LUTS). The amount of work that was required to create an effective multidisciplinary clinic (including the planning, fund-raising, staff recruitment, and creation of patient materials) should not be underestimated, and the authors should be congratulated for taking on this challenge.

The popularity of the clinic over a short period of time attests to the demand for these services in the general population. This model represents an important step forward in the management of urinary symptoms. It addresses the fact that many family physicians either do not feel comfortable evaluating and managing LUTS or they do not have time. While chronic conditions, such as diabetes and hypertension, are a cornerstone of their practice and training, LUTS (which are equally prevalent) are often immediately referred or referred after a single trial of alpha blocker/overactive bladder medication; imagine if patients with hypertension were referred to a cardiologist without trying any medications! Issues such as fluid intake, pelvic floor dysfunction, and normal changes with aging represent basic contributors to LUTS and they do not need a specialist assessment to address.

An important point raised by the authors of this study is that urologists are trained as surgeons, and the way urology residency is structured is to reward seniority with surgical exposure and skill development. This is the specialized expertise that urologists have that no other speciality can provide. Most patients with LUTS do not need a surgeon, and once this has been established, care can be delivered by alternate providers. This non-specialist care is likely less expensive and more patient-centred; the increased ability of non-specialists to provide ongoing care would hopefully break the often-observed cycle of multiple referrals to specialists for the same symptoms.

Urologists should still be the experts for the management of LUTS. However, it is important that we empower other care providers to take on the basic management of this population. Hopefully, new funding models will allow physician assistants, nurse practitioners, or interested family physicians to take on roles as medical experts in functional urology and expedite care for patients.

Competing interests: The author reports no competing personal or financial interests related to this work.

\section{References}

1. Hartmann KE, MCPheeters ML, Biller DH, et al. Treatment of overactive bladder in women. Evid Rep Technol Assess (Full Rep) 2009;(187):1-120.

2. Stewart WF, Van Rooyen JB, Cundiff GW, et al. Prevalence and burden of overactive bladder in the United States. World J Urol 2003;20:327-36.

3. Abrams $\mathrm{P}$, Kelleher $\mathrm{CJ}$, Kerr LA, et al. Overactive bladder significantly affects quality of life. Am J Manag Care 2000;6(11 Suppl):S580-90.

4. Tubaro A. Defining overactive bladder: Epidemiology and burden of disease. Urology 2004;64:2-6. https://doi.org/10.1016/i.urology.2004.10.047

Correspondence: Dr. Blayne Welk, Division of Urology, Department of Surgery, Western University, London, ON, Canada; bkwelk@gmail.com 